\title{
La conquista y colonización de Maranhão- Grão Pará: el gran proyecto de la Monarquía Hispánica para la Amazonia brasileña (1580-1640) $)^{1}$
}

AUTOR

José Manuel Santos Pérez

manuel@usal.es

* Profesor titular de Historia de América del Departamento de Historia

Medieval, Moderna

y Contemporánea de la USAL.

\author{
A conquista e colonização do Maranhão-Grão Pará: o grande projeto da Monarquia \\ Hispânica para a Amazônia brasileira (1580-1640) ${ }^{1}$
}

The Conquest and Colonisation of Maranhão-Grão Pará: the Hispanic Monarchy's Large Project for the Brazilian Amazon Region (1580-1640)

\section{RESUMEN:}

La zona conocida a principios del siglo XVII como Maranhão abarcaba la práctica totalidad de la Amazonia. Famosa en la Europa renacentista por ser una región de múltiples mitos y leyendas, comenzó a materializarse como un atractivo territorio para diferentes sociedades europeas interesadas en la expansión y colonización de los territorios de ultramar. A medida que estas iniciativas se iban concretando, la doble corona hispano-lusa fue organizando una respuesta frente a ellas que a partir de 1618 se convirtió en un gran proyecto militar, religioso, administrativo y de colonización para una región que lejos de ser motivo de confrontación entre los sistemas políticos portugués y español, sirvió como gran plataforma para un objetivo integrador dentro de la Unión lbérica. Fue durante este periodo que se pusieron las bases para la posterior colonización efectiva europea del territorio, tarea que se dilató más de dos siglos.

\section{RESUMO:}

A princípios do século XVII, a região conhecida como Maranhão englobava praticamente toda a Amazônia. Famosa na Europa renascentista por ser uma região de muitos mitos e lendas, o território passava a ser um atrativo para diferentes sociedades europeias interessadas na expansão e colonização dos territórios no ultramar. A medida em que essas iniciativas se concretizavam, a coroa hispano-lusa foi organizando uma resposta às mesmas que, a partir de 1618 , se converteu em um grande projeto militar, religioso, administrativo e de colonização para uma região que, longe de ser motivo de confrontação entre os sistemas políticos português e espanhol, serviu como grande plataforma para um objetivo integrador dentro da União lbérica. Foi durante esse período que se fundaram as bases para a posterior efetiva colonização europeia do território, tarefa que se dilatou durante mais de dois séculos.

\footnotetext{
ABSTRACT:

The region known as Maranhão at the beginning of the 17th century encompassed the whole Amazon domain. Famous in Renaissance Europe due to the numerous myths and legends that emerged there, it started to be attractive for different societies in Europe interested in the expansion and colonisation overseas. When these initiatives started to materialize, the double Luso-Spanish crown reacted against them and, from 1618 onwards, launched an important project that included military, religious, political and colonisation goals. Far from being a region in dispute for Spanish and Portuguese political systems, it served as a platform for an integration goal within the Iberian Union. It was during this period that the bases for the future European colonization of the region were established, a task that lasted more than two centuries.
} 


\section{Introducción}

Los años finales del siglo XVI y los primeros del siglo XVII contemplan una serie de cambios importantes en las tendencias que la Monarquía Hispánica había tenido desde los tiempos de la gran herencia de Carlos I. La muerte de Felipe II se llevó a la tumba la agresiva política de expansión española, que tuvo sus momentos culminantes en la herencia/anexión de los territorios portugueses en 1580-1581 y en el fallido ataque a Inglaterra en 1588. Según la visión tradicional, la Monarquía Hispánica, exhausta por años y años de guerras contra enemigos múltiples, decidió arriar velas y afrontar unos años de tregua, replegando los ejércitos en Flandes y firmando la paz con sus principales enemigos. Autores más recientes evalúan el llamado periodo de la Pax Hispánica no como una etapa de repliegue por razones de debilidad sino como una decisión estratégica que permitiría reorganizar la economía y el sistema bélico y esperar a momentos mejores para lanzar un contrataque definitivo que supusiera la implantación del Rey Católico y su Monarquía Universal como Señor del orbe y garante supremo de la "verdadera" fe católica (Allen, 2001; García, 1996; Olival, 2008). Si esto fue así no llegó a plasmarse de manera clara pues a la defenestración de Lerma le siguió poco después la muerte de Felipe III y la llegada al trono de su hijo Felipe IV y de su valido, el Conde-Duque de Olivares, dispuesto como pocos a garantizar una mejor distribución de las cargas económicas y de los esfuerzos bélicos entre los diversos reinos de la Monarquía.

Esta visión, sin embargo, adolece de un gran defecto, que poco a poco se está subsanando: una visión eurocéntrica de la Monarquía Hispánica que, no lo olvidemos, contó durante los años 1580 a 1640 con inmensos territorios ultramarinos que solo en la última parte del siglo $\mathrm{XVI}$ comenzaron a dar réditos importantes y que se encontraban amenazados por múltiples y codiciosos enemigos que esperaban obtener beneficios mediante el comercio, los ataques a poblaciones costeras o el pillaje de las numerosas flotas que cruzaban el Atlántico en uno u otro sentido. Es por lo tanto con este telón de fondo de la reorganización americana que debemos aproximarnos a este periodo que va de las dos últimas décadas del siglo XVI hasta los años 1630-1640 del siglo XVII, fechas en las que se produjo, en el territorio de la América portuguesa, la conquista y primer poblamiento de las regiones del norte, desde el Río Grande, pasando por Ceará, hasta confluir en el inmenso y enigmático territorio del Maranhão, lo que hoy conocemos como la Amazonia. No es exagerado decir que, en aquellos tiempos de repliegue bélico en Europa, las diversas campañas de conquista del territorio del norte de Brasil, y en concreto, la campaña de conquista de Maranhão-Pará, se contaron entre los más importantes movimientos militares de la época y ampliaron de manera sustancial los territorios bajo dominio efectivo de la Monarquía.

Esa conquista del Maranhão-Pará tuvo unos antecedentes que debemos presentar para entenderla; por un lado, la importancia que cobró el territorio de la América portuguesa en esos años entre siglos y por otro lado los contactos iniciales que tuvieron los europeos con el territorio maranhense desde el descubrimiento de Orellana en 1542.

Algunos de los autores que trataron en el pasado el tema de la unión de coronas ibéricas o Unión lbérica, identificaron como uno de sus más importantes efectos en Brasil el de la expansión hacia el norte (Wright \& Mello, 1997). La América portuguesa tuvo un muy importante desarrollo territorial durante estos años finales del siglo XVI y sobre todo durante los años iniciales del siglo XVII. Dentro de la estrategia general de los diferentes reyes Habsburgo para el territorio de Brasil, la conquista y colonización del territorio norteño se presentó siempre como una importante prioridad, reforzada en los años iniciales del reinado de Felipe III, lo que desembocó finalmente en la conquista de la región del Maranhão-Pará en la segunda década del siglo XVII. La región había sido protagonista en muchos de los relatos que llegaron o que se escribieron en Europa durante el 
siglo XVI y los inicios del siglo XVII. En muchos de ellos se identificaba a la región con El dorado o el mítico reino de las Amazonas, pero aparte de las fantasías todos o casi todos estos relatos coincidían en una idea, que se expresaba perfectamente en el mapa de De Vaulx de 1613 (Imagen 1): el Amazonas era una región situada entre el Estado do Brasil y el Perú, era su nexo de unión y podía ser utilizado o bien como vía de entrada o bien como vía de salida para la producción de plata de Potosí.

Brasil representó una adquisición secundaria cuando en 1580-1581 se incorporaron los territorios portugueses de ultramar a los dominios de Felipe II. Inmediatamente, el rey Prudente envió una flota a esa región al mando de Diego Valdés. El objetivo principal era explorar el estrecho de Magallanes, pero la flota recorrió la costa de Brasil, hizo escala en São Vicente, y a su regreso paró en Salvador y desde allí mandó una expedición para explorar el territorio de Paraíba, fundando el Forte de São Felipe que daría origen al asentamiento de Filipeia (Vilardaga, 2010, pp. 51-80).

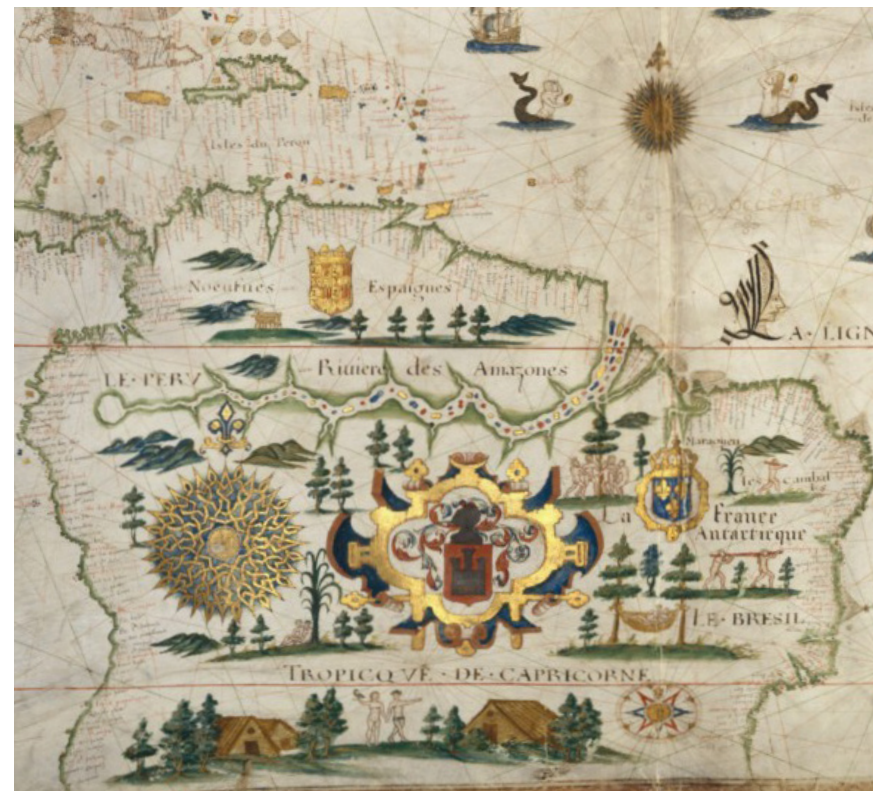

Imagen 1. Vaulx, P. de (1613). Carte de l'Océan atlantique. París: Biblioteca Nacional de Francia. Recuperado de [https://gallica.bnf.fr/ark:/12148/ btv1b5906245s/f1.item]. Consultado [04-01-2019].

Se ha especulado mucho sobre si los Habsburgo españoles tuvieron o no una estrategia para el territorio de la América portuguesa. Posiblemente no se planteó algo así en el ámbito de la corte a finales del siglo $\mathrm{XVI}$, aparte de la mencionada flota de Valdés que debía actuar como carta de presentación del poderoso rey Prudente en los territorios lusos de ultramar. En principio Brasil no representaba una prioridad para la monarquía a la altura de 1580. En lo que a los territorios americanos hispanos se refiere, el tema fundamental continuaba siendo cómo garantizar una producción constante y creciente de plata y unos envíos seguros de la misma hasta la península ibérica. Para conseguir esto se llevaron a cabo las reformas del virrey Toledo en Perú que, al introducir el procedimiento de la amalgama de mercurio y el sistema de mano de obra forzosa de la mita, garantizaban una mayor producción y un suministro seguro de mano de obra. Al mismo tiempo se consolidaba el sistema de flotas y galeones, los convoyes anuales con escolta militar que hacían más segura la Carrera de Indias. Lo que le correspondería al desconocido e ignoto territorio de Brasil en este esquema era un papel de mero espectador, a no ser que algo o alguien convenciera a las autoridades monárquicas en Madrid de que este territorio podía ser importante en la estrategia de defensa del Atlántico. Esto es lo que parece que poco a poco se fue fraguando en los años finales del siglo XVI, tras el regreso de la flota de Valdés, y fundamentalmente en los momentos iniciales del siglo XVII.

Si es complicado hacernos una idea de lo que representaba Brasil en el seno de la corte Habsbúrguica, aún más lo es intentar entender qué conocimiento se tenía del territorio amazónico. Varios de los cronistas o autores de "relaciones" durante el siglo XVI habían incluido este territorio remoto en sus obras. Tanto Cieza de León como Lópe de Gómara, pasando por Acosta u Oviedo habían hecho comentarios sobre el gran río de las Amazonas, confundiéndolo o integrándolo casi siempre con las otros dos grandes corrientes fluviales del Orinoco y el Maranhão (Cardoso, 2012, pp. 57-64). Otros aventureros como el inglés Raleigh habían loado también las ventajas de la posesión de este territorio, llegando a proclamar que el rey que lo poseyera tendría una ventaja muy importante entre las diferentes naciones europeas (Cardoso, 2012, p. 114).

Los hombres que participaron en la conquista de Maranhão propagaron también la conexión entre esta región y Perú en cuanto tuvieron ocasión de hacerlo. Es lo que expresó el sargento mor do Estado do Brasil, Diogo de Campos Moreno, cuando en el Livro da razao do Estado do Brasil comenzó diciendo que "Brasil es la parte 
oriental del Perú" (Moreno, 1955). O lo que se puede ver perfectamente representado en el ya citado mapa de De Vaulx (Imagen 1), donde el Amazonas nace en un lago situado en el Perú, al que según el mapa y los testimonios de la época se podría llegar navegando incluso con las naves de mayor porte (Cardoso, 2012, p. 89).

Además, en los primeros compases del siglo XVII se aireaba en la corte de Madrid el peligro constante que significaba la presencia de los dos mayores enemigos del rey católico: los rebeldes holandeses y los criptojudíos, que, según diversos testimonios, abundaban en las costas e incluso en el interior de Brasil.

No solo a los holandeses les llamaba la atención la región. En los primeros años del siglo XVII merodearon por la desembocadura del Amazonas o por territorios aledaños como Maranhão, diversas flotas de italianos, ingleses, irlandeses y franceses que tenían diversas pretensiones, desde organizar el comercio con los indígenas hasta formar colonias permanentes.

En los primeros años del siglo aparecieron en la zona expediciones enviadas por el Gran Duque de Toscana, mantenidas en secreto porque, aunque interpretaba que él también era vasallo del Rey Católico, dudaba que este pensara lo mismo y le permitiera el acceso a las posesiones americanas (Brege, 2014). Poco tiempo después aparecieron en la zona expedicionarios ingleses e irlandeses que, en coalición con algunas de las expediciones holandesas, lograron establecer puntos de contacto e incluso asentamientos en zonas cercanas al llamado Cabo del Norte, en el lado norte de la desembocadura del río, como veremos más adelante.

El intento más acabado y peligroso, en opinión de los burócratas de la monarquía hispánica, fue el segundo proyecto francés de conquista y colonización de un territorio del litoral brasileño, después de aquel llevado a cabo por Nicolas Durand de Villegagnon en la bahía de Guanabara, la llamada France Antartique. Este nuevo proyecto, que ha pasado a ser conocido como la France equinoxiale, fue considerado en el momento como una gran amenaza para el conjunto de las posesiones americanas, y no solo para la América portuguesa. De las comunicaciones entre Felipe III y las autoridades on the spot, principalmente el gobernador del Estado de Brasil en la época, Gaspar de Sousa, se desprende que la presencia en la desembocadura del río Maranhão de un destacamento de franceses, que habían llegado a fundar un fuerte en la isla de São Luis, constituía un gran desafío (Salvado \& Münch, 2001). Se dieron por lo tanto instrucciones para organizar un ataque, e incluso promesas de "navíos de socorro" y tropas que debían ser enviadas desde la península ibérica, aunque estas nunca llegaron, o lo hicieron con cuentagotas.

Las expediciones luso-brasileñas fueron organizadas y financiadas por las autoridades locales desde Pernambuco, cuya capital, Olinda, se había convertido momentáneamente en la capital del Estado de Brasil, pues fue allí donde se estableció el governador geral Sousa para coordinar mejor las operaciones. Parece también que esto era un reconocimiento de que la capacidad económica, de reclutamiento de hombres y de visión del conjunto de la América portuguesa, era superior en Pernambuco de lo que era en la propia sede del gobierno portugués en América, la ciudad de Salvador. En efecto, desde Olinda fueron enviadas diversas expediciones, primero de reconocimiento y después de conquista de la zona ocupada por los franceses. No eran las primeras. De inicios del siglo XVII data una primera expedición portuguesa a la zona del Maranhão capitaneada por Pero Coelho de Sousa en tiempos del gobernador Diogo Botelho. Esta expedición tenía ya como objetivo reconocer la zona y explorar las posibilidades de llevar a cabo un asentamiento permanente, aunque esto último no se produjo. En ella participó Martim Soares Moreno, que después protagonizaría la fundación del primer fuerte portugués en Ceará y una expedición en 1613 que, en tiempos en que los franceses ya se habían establecido en la zona, obtendría algunas informaciones importantes sobre rutas de navegación y posible cooperación de los indígenas con el intento portugués de conquista.

La operación militar en sí se produjo entre 1614 y 1615 y consistió en varias expediciones militares por mar y tierra capitaneadas por Jerónimo de Albuquerque, Alexandre de Moura y el sargento mayor de Brasil, Diogo de Campos Moreno, que tras haber sido cesado del cargo por Felipe III, volvió a ser investido con 
el mismo puesto para llevar a cabo esta gran operación militar. El éxito fue relativo pues si en algunas crónicas se habla de una victoria militar de los portugueses con algunos tintes de heroicidad (se habrían enfrentado tan solo 200 portugueses a un ejército combinado francés-indígena de más de 2000 hombres), lo cierto es que ni los efectivos portugueses eran tan escasos, pues contaban también con una numerosa fuerza de indios flecheiros, ni la batalla se saldó con una victoria portuguesa sin más, pues tras ella vinieron intensas negociaciones tanto en la zona como en Europa. En efecto, el propio Diogo de Campos Moreno viajó a Lisboa con uno de los oficiales franceses para tratar de los términos de una paz que se habría firmado con los galos y que daría a su comandante Daniel de la Touche, Sieur de la Ravardiere, libertad de movimientos. Parece ser que los mandos portugueses, que desconocían la región y tenían una información escasa sobre la misma, se quedaron impresionados con los amplios conocimientos del comandante francés, que no solo dominaba la navegación por los complicados canales entre las islas, sino que también entendía lenguas indígenas y había trabado excelentes relaciones con los tupinambá locales. Se llegó a pensar en la necesidad de dejar libre al jefe militar francés y pasarlo al bando lusoespañol para aprovecharse así de sus conocimientos (Cardoso, 2012, p. 132). En Lisboa y Madrid se deshicieron estos términos de armisticio, pues por un lado fueron considerados deshonrosos y por otro se entendieron como una trampa del astuto capitán, que de ese modo ganaría tiempo para esperar la llegada de un operativo francés, o combinado de franceses y holandeses, para liberar al destacamento y volver a instalar el dominio galo en la región. El comandante francés sería después enviado a Lisboa, donde no sufrió los rigores de las mazmorras portuguesas durante su cautiverio sino que fue "agasajado" como su figura requería por petición del virrey de Portugal².

Una vez conquistado el fuerte francés se vio clara la necesidad de, para defenderlo, tener también un dominio de la zona más hacia el norte, la de desembocadura del Pará y los otros tributarios en la desembocadura del Amazonas, lo que determinó la fundación de Belém do Pará en 1616. Esta "cabeza de puente" sería fundamental también para poder expulsar de esa zona más al norte a los holandeses y zelandeses que se habían instalado en las márgenes del Xingú y otros ríos con el objetivo de fundar colonias permanentes (Chambouleyron, 2006; Cardoso, 2008; Cardoso, 2012; Marques, 2014).

No podemos perder de vista el contexto de esta conquista en la estrategia de los Habsburgo para la América portuguesa. La existencia de amenazas constantes de invasión hizo que los Austrias españoles optasen por una contra estrategia de defensa de los territorios del Atlántico Sur. El territorio de la América portuguesa en su conjunto empezó a cobrar una importancia especial en los años finales del siglo XVI y los iniciales del XVII. Ello determinó que debía ser defendido tanto por la posibilidad de la existencia de yacimientos de metales preciosos en su interior, lo que haría de él "un nuevo Perú" como por ser un gran escudo de defensa del territorio de las minas. Sin embargo, el sistema defensivo de la América portuguesa era muy frágil y exigía la construcción de una línea de defensa en el litoral para controlar el territorio y evitar que fuese conquistado por los numerosos enemigos que lo codiciaban. Durante los últimos años del reinado de Felipe II y los primeros del de Felipe III hubo una gran actividad de construcción de fortalezas en el territorio luso americano y fueron enviadas varias flotas de socorro como respuesta a las amenazas ya comentadas y las numerosas informaciones que llegaban de las embajadas europeas sobre planos de los enemigos de la monarquía para ataques en la región sur del Atlántico. No es exagerado decir que esta línea de fortalezas construidas en este periodo fue el origen de una buena parte de las ciudades costeras del Brasil contemporáneo.

A pesar de esta línea argumental, que convencía a las autoridades monárquicas de llevar a cabo un refuerzo del sistema defensivo del territorio brasileño, debemos tener en cuenta que en la concepción de la defensa que tenía el sistema militar de la Monarquía, la responsabilidad en este campo no siempre era del rey. La cabeza del imperio debía ocuparse de la defensa naval, pero la defensa en tierra debía ser organizada y financiada por la propia población local. Este es uno de los asuntos que necesitan ser investigados de manera específica, pues aún no tenemos claro cómo se financió la construcción de las fortalezas costeras de finales del siglo XVI y principios del XVII en Brasil. De manera general podemos decir que los recursos se 
obtuvieron de manera local, por medio de lo recaudado a través de impuestos ordinarios, como el diezmo, o con impuestos extraordinarios como los de la sal y el vino que se creaban con la justificación de que servirían para el refuerzo de las edificaciones de defensa, sobre todo en Salvador de Bahía ${ }^{3}$. En ocasiones se utilizaba lo recaudado por el arrendamiento de monopolios regios como el palo brasil o la pesca de la ballena, $u$ otros impuestos correspondientes a la hacienda regia como los pagos en aduanas o derechos de entrada y salida de mercancías. Se ha calculado que los gastos militares del Estado do Brasil en los primeros años del siglo XVII representaban al menos un $50 \%$ del total de los gastos, llegando al $60 \%$ en los años de la conquista de Maranhão (Costa, 1985).

A medida que iba transcurriendo el siglo XVII se fue considerando que el problema defensivo no afectaba únicamente a la zona costera de Brasil. Según diversas informaciones que llegaban desde este territorio, los holandeses habían empezado a transitar las dos vías más importantes de comunicación de la costa de Brasil con el interior, que podían ser utilizadas para llegar hasta el corazón argentífero del imperio: la vía del sur a través del planalto de Piratininga y la vía del norte a través del Amazonas. Es verdad que buena parte de estas noticias eran propagadas por los jesuitas, lo que hace desconfiar que fueran ciertas, pues podían estar relacionadas con la intención de los padres de la Compañía de obtener mayores destacamentos militares en la zona aledaña a São Paulo para controlar así las incursiones violentas de los que vendrían a ser denominados más tarde bandeirantes. Según los testimonios de los jesuitas, en los caminos de acceso al sertão paulista estarían entrando judíos de origen neerlandés para llevar a cabo un reconocimiento de los senderos indígenas, lo que estaría relacionado con un posible intento por alcanzar la montaña de plata de Potosí por esta vía desconocida, poco transitada y desde luego, apenas vigilada por las tropas españolas. Si por el sur el acceso a Potosí podría realizarse por tierra, la idea de poder realizarlo por agua estaba siendo acariciada por los holandeses en el norte de Brasil, donde según diversos testimonios los bátavos estarían ya construyendo fuertes en la segunda década del siglo XVII. Estas informaciones eran mucho más exactas y tenían mayores visos de ser ciertas que las propagadas por los jesuitas en el sur. También eran mucho más preocupantes. En función de las noticias que llegaban, los holandeses estarían organizando una gran flota que se uniría a barcos ingleses para ocupar algún territorio dentro del Amazonas. Era por lo tanto posible que se produjera una especie de "Unión de Armas" de las potencias enemigas protestantes, incluso con la ayuda de Francia, para llevar a cabo un gran ataque sobre esa parte de la Monarquía que tenía una ocupación débil por parte hispano-lusa. Esta idea, por supuesto, era más fantasía que realidad, pero en el clima de amenaza constante que se vivía en la segunda mitad del siglo XVI y con las informaciones enviadas desde Brasil, parecía posible. Era muy probable también que los franceses intentaran algún tipo de contraataque para recuperar la zona perdida con la conquista de Maranhão. Debemos tener en cuenta también que la presencia de neerlandeses en el litoral brasileño durante las primeras décadas del siglo XVII era constante, tanto en forma de incursiones militares, como en grupos de comerciantes o incluso con intentos de crear colonias permanentes, como fue el caso de las que se organizaron en el Amazonas. Estas colonias no eran específicamente de holandeses sino de sus vecinos zelandeses, procedentes fundamentalmente de la ciudad de Vlissingen o Flesinga, en el oeste de la provincia neerlandesa de Zelanda. Baltasar de Moucheron, personaje procedente de esta región, había realizado expediciones al Amazonas ya a finales del siglo XVI. Después, en la segunda década del siglo XVII, había ya un proyecto serio de colonización en la zona. El historiador Edmunson, que escribió a inicios del siglo XX sobre las actividades inglesas y holandesas en Brasil a finales del siglo XVI y principios del XVII, informó de que antes de 1616 existió ya un asentamiento neerlandés en el lugar donde los portugueses construirían después el fuerte do Desterro, en la margen derecha de la desembocadura en el Amazonas del río Uacarapy. Según Edmunson, cuando la ciudad zelandesa de Vlissingen fue liberada por los ingleses del dominio español, en 1616, fueron lanzadas dos expediciones de colonización, una para Essequibo y otra para el Amazonas (Edmunson, 1903, p. 652). El fundador de Belém do Pará, Francisco Caldeira, daba noticias sobre el asentamiento zelandés en el mismo año de la fundación del nuevo asentamiento portugués, en 1616. Un visitante francés le dio información de que los zelandeses y los holandeses tenían 250 o 300 hombres en dos fortalezas de madera y dos molinos de azúcar en el río "Ginipape", probablemente el Jenipapo o Perú, donde más tarde sería construida la 
fortaleza portuguesa del Destierro. El historiador neerlandés Wim Klooster abunda sobre la cuestión en una reciente obra. Según su relato, los zelandeses en realidad fueron asistentes de los ingleses y los irlandeses en sus intentos de colonización aguas arriba del delta del Amazonas a partir de 1611. James I habría prohibido a los súbditos ingleses fundar asentamientos en los territorios españoles en América, pero esta disposición no se habría aplicado en el caso de los ingleses residentes en la ciudad zelandesa de Flesinga, donde habitaban numerosos soldados y comerciantes. Los ingleses se embarcaron en naves zelandesas y se integraron en los asentamientos de estos en el Amazonas en dos momentos, en 1611 y en 1616, cuando 130 hombres y mujeres ingleses, incluyendo 14 familias, se embarcaron hacia el río Amazonas. Los ingleses salieron de Flesinga y Rammekens, dos ciudades zelandesas en las que la mayoría actuaban como soldados en las guarniciones locales. Ambas ciudades habían sido otorgadas a Inglaterra por las autoridades neerlandesas como fianzas por la ayuda prestada por Isabel I a partir de 1585 en la guerra contra Felipe II. Los impuestos de ambas ciudades se otorgaron a Inglaterra en compensación por la ayuda militar. En el año de 1616 los Estados Generales pagaron el resto de la deuda y redimieron a las ciudades de pagar el impuesto a Inglaterra, lo que determinó la desbandada de las guarniciones inglesas. Muchos de estos soldados decidieron emprender la aventura amazónica junto con los zelandeses (Klooster, 2016).

Los neerlandeses habían construido por lo menos tres fuertes en la región de Grão Para-Maranhão, fundamentalmente en las márgenes del río Xingú y del Amazonas, unos con madera y otros más robustos con adobe (Garrido, 1940). La fortaleza más importante de los bátavos era la que llamaban "Corupá", conocida también como fortaleza de Tucujús o Mairocay, situada en la cercanía de la Isla de Gurupá y de la desembocadura del río Xingú, en la margen norte del río Amazonas. Este fuerte estaba destinado a proteger los dos asentamientos neerlandeses más conocidos: los fuertes o campamentos de Orange (o Muturu) y Nassau, en las márgenes derecha e izquierda del Xingú, respectivamente. Los dos asentamientos tenían que ver con los esfuerzos de los habitantes de Flesinga de establecer relaciones comerciales con las poblaciones nativas de las zonas aguas arriba de la cuenca amazónica.

Habría por lo tanto una empresa híbrida o mixta que combinaba agentes comerciales a lo largo del río, los fuertes mencionados, la colonia de los zelandeses (con muchos ingleses) de Flesinga y una fuerza militar limitada que serviría de cobertura a los esfuerzos colonizadores. Parece ser que la flota capitaneada por Pieter van der Does en 1599 podría haber tenido como objetivo dar soporte a estos asentamientos y fue apoyada por el Moucheron mencionado anteriormente. La flota de van der Does contaba con 75 barcos y 8 mil soldados y marineros. Era una flota muy importante y sus objetivos no parece que se limitaran a cobrar piezas en acciones de piratería en el Atlántico. Es posible que además del apoyo puntual a los asentamientos amazónicos, el principal objetivo de esta flota fuese llevar a cabo una invasión de algún punto de la costa de Brasil. La flota atacó Las Palmas de Gran Canaria y después la isla de São Tomé. Allí el complejo microbiano de la costa africana se cobró su precio: la expedición holandesa sufrió una epidemia de malaria que afectó a miles de soldados y marineros, obligándolos a cambiar de planes. Una parte de la flota regresó a los Países Bajos, pero se envió una escuadra de siete barcos a Brasil donde puso sitio a la ciudad de Salvador y combinó el comercio con los saqueos a las plantaciones del Recôncavo (Boogaart, 1992, p. 78). Que no hubiera una invasión holandesa previa a 1624 de Salvador u otra ciudad importante brasileña, o que no se hubieran reforzado suficientemente los asentamientos holandeses en el Amazonas, fue por lo que parece más una cuestión de suerte o coyunturas desfavorables para los holandeses que un acierto en las acciones defensivas emprendidas por los locales y por la doble monarquía luso-española en el territorio de Brasil.

Los informes alertando de una abundante y amenazadora presencia extranjera en la región del Maranhão no dejaban de llegar a la corte de Madrid. Dentro de estos numerosos informes destaca el del capitán Manuel de Sousa de Eça, de 1615, titulado "Derrota del rio de las Amazonas dada por el capitán Manuel de Sosa Dessa al Señor Virrey", en el que informaba de la presencia de extranjeros, pero que también hacía referencia a un hecho muy preocupante. Eça escribía lo siguiente sobre los peligros de la presencia foránea en la región: 
Y también porque este río va a dar al Pirú, y se tiene que es todo navegable, que lo son trecientas y tantas leguas, se sabe de personas que ya lo navegaron, y podrá el enemigo irlo conquistando y poblando y llegar al Pirú y molestarnos a todo lo qual se puede atajar en estos principios con bien poca costa, y no faltará quien sirva a su Magestad en esta conquista, dando lo necessario y porque también deste dicho río se podrá sacar la plata que viene del Pirú, con mucho menos costa de lo que se haze al presente, por quanto el Río es navegable todo (Cardoso, 2012, p. 202) ${ }^{4}$.

Más tarde, en 1622, poco después de su nombramiento, el capitán mayor de Pará, Bento Maciel Parente, escribía al rey con la intención de informar sobre la presencia extranjera en la región del Cabo del Norte. Dos "flamencos" le informaron que:

na entrada da barra do rio das Amazonas, da banda e junto ao Cabo do Norte, estavam em huma povoação cento e cinquenta soldados framengos, pechilingues, irlandeses e ingreses, e dezião aguardar neste mês de mayo passado 120 naos grandes de mercadores com 400 homes cada huma que ião povoar naquella costa da qual tiravão pao de tinta, tabaco, Carapurú, Vuren, Cujás, algodão e outras mercadorias (...).

Junto con esta información iba una petición de hombres y medios para llevar a cabo la expulsión de los extranjeros, que recibió respuesta real favorable, sugiriéndole que debía contar con la ayuda de los indígenas locales. Poco después de realizar la petición, Maciel Parente recibió al capitán Luis Aranha de Vasconcelos, que llegó desde Madrid con la misión de expulsar a los invasores neerlandeses. El envío de Vasconcelos tenía un trasfondo mayor que una simple respuesta a la petición de Maciel Parente. En ese mismo año de 1622 se había presentado un arbitrio en Madrid que propugnaba la colonización de todo el norte de Brasil, siendo su autor más probable el mismo Vasconcelos. El documento hablaba de la necesidad de protección de los territorios de la Corona de Castilla en América y de las flotas de Indias. A pesar de que en la propuesta se contemplaba al Reino de Portugal como el responsable de llevar a cabo esta iniciativa, finalmente Luis Aranha Vasconcelos fue enviado por Madrid para hacer efectiva la expulsión de los extranjeros sin el conocimiento de las autoridades portuguesas (Marques, 2014, p. 267).

Frei Vicente Salvador, por su parte, en la Historia do Brasil de 1627, hacía una exposición de las motivaciones y circunstancias de la llegada de Vasconcelos a la región norte de Brasil en 1622:

Mandou sua Majestade o capitão Luiz Aranha de Vasconcelos em uma caravela de Lisboa a descobrir e sondar o dito rio pelo cabo do Norte, por dizerem que por ali podia tirar a sua prata do Potuci, com menos gasto, e para este efeito Ihe deu provisão para os capitães de Pernambuco, Rio Grande, Maranhão, e Pará lhe darem tudo o que fosse necessário; em virtude das quais lhe deu Mathias de Albuquerque em Pernambuco uma lancha com 17 soldados, e o piloto Antônio Vicente, mui experimentado naquela navegação, e lhe carregou na caravela oito mil cruzados de diversas sortes de fazendas por conta de Sua Majestade para a fortaleza do Pará, que havia dois anos se não provia com pagas, nem algum socorro, pelo que estava mui necessitada, e André Pereira Timudo, capitão-mor do Rio Grande, Ihe deu quatro soldados, dos quais era um Pero Gomes de Gouvea seu alferes, que o capitão Luiz Aranha fez capitão da lancha (Salvador, 1627, p. 191).

Tanto la existencia del arbitrio como el testimonio de Frei Vicente son muy interesantes, pues dan cuenta de la existencia de proyectos castellanos, desarrollados al margen de las autoridades portuguesas, para llevar a cabo la colonización del territorio amazónico. Muy llamativa es la razón esgrimida por el cronista Salvador: la posibilidad de que pudiera sacarse la plata desde Potosí directamente al Atlántico a través del Amazonas, que coincidía con lo expresado por Manuel de Sousa D’Eça. En ese sentido se manifestaba también Brandônio, el personaje protagonista de la obra Diálogo das grandezas do Brasil, de 1618, atribuida a Ambrósio Fernandes Brandão, cuando cuenta la historia del hermano de un "perulero" que, huyendo del virrey de Perú por un asunto legal, acabó descendiendo por un río y a través de tres cataratas y con la 
ayuda de los indígenas acabó en la desembocadura del río Amazonas. Según Brandônio, este método de navegación debía ser informado al rey de España para establecer una línea directa con Perú a través del río (Brandão, 1618, fols. 12-12v) ${ }^{6}$.

El resultado del envío de Luis Aranha y sus refuerzos a Pará fue que, en 1623, junto con la fuerza reunida por Maciel Parente, atacaron las bases neerlandesas en la zona y pudieron destruir el fuerte y expulsar a los pobladores del Xingú. El mismo Bento Maciel Parente construiría allí el fuerte portugués de Santo Antonio do Gurupá, principal bastión portugués en la región durante lo que quedaba del siglo XVII. Más tarde, en 1625, Pedro Teixeira destruiría el asentamiento de "Ginipape".

Por lo tanto, es posible afirmar que con todo este conjunto de testimonios, la Corona se convenció de que el Amazonas podía ser la puerta de entrada hacia Potosí para los enemigos de la Monarquía. Parece que esta posibilidad es la que convenció a Felipe III de la necesidad de llevar a cabo todo un proyecto de conquista, expulsión de extranjeros y colonización del territorio amazónico desde el Maranhão al Pará, que se tradujo en un plan militar de conquista, una acción religiosa de conversión de los indígenas, un programa de colonización con familias de azorianos y una reforma administrativa, con la creación de un estado en Maranhão diferenciado del Estado de Brasil. Este no fue un proyecto español únicamente, sino que contaba con participación portuguesa, pernambucana y fundamentalmente indígena, en lo que a la parte militar se refiere. Como ya se ha mencionado, la campaña militar fue uno de los más importantes eventos militares ocurridos durante un reinado que, por otro lado, se caracterizó más por la búsqueda de la paz y la consolidación de los territorios de la Monarquía que por la ambición de ampliar conquistas.

En realidad, aunque el objetivo para la región parecía claro, someterla a los designios del rey católico y librarla de enemigos, al principio no hubo un plan general o una estrategia perfectamente pensada para conseguirlo. Entre 1600 y 1618 hubo diversas acciones, no siempre coordinadas, para la región. La expedición de Pero Coelho de Sousa y la de Martim Soares Moreno de 1613 fueron las primeras acciones. Después vendría la conquista de la France equinoxiale, casi tirada por tierra por las negociaciones de los locales. A continuación, derivada de esta conquista, la fundación de Belém do Pará. Después la llegada de Luis Aranha Vasconcelos, que sí tenía detrás un plan (castellano) de conquista y colonización, pero que no contaba con medios suficientes y que se apoyaba demasiado en la buena voluntad de los locales. El resultado fue modesto pero importante, pues se logró expulsar a los neerlandeses, ingleses e irlandeses que se habían asentado y habían llegado a construir fuertes en la zona del Xingú y alrededores.

A partir de 1618, sin embargo, sí se puede constatar la existencia de una estrategia planificada para la zona. El rey convocó a Lisboa a un "comité de expertos" en las cuestiones maranhenses para asesorarlo en las importantes decisiones que habrían de tomarse. Estaba compuesto por Alexandre de Moura, capitán de la conquista, y los exgobernadores Gaspar de Sousa y Diogo de Menezes.

El hecho de que Luis Aranha de Vasconcelos emprendiera su misión sin conocimiento de las instituciones portuguesas de la Monarquía tenía que ver con las grandes dudas que existían sobre si el territorio amazónico se encontraba o no dentro de los límites portugueses en América. Es decir, a pesar de la unión de las coronas de 1580-81, siguió habiendo una separación clara de los ámbitos de actuación de cada uno de los reinos, pero esa separación era muy dudosa tanto en la región amazónica como en la región platina. Movimientos portugueses de expansión hacia el interior y de presencia constante en las rutas del Río de la Plata, llevaron a diversos miembros de los consejos reales a expresar quejas sobre esta cuestión y a manifestar la necesidad de frenar esos movimientos expansivos a costa de los territorios castellanos en América (Marques, 2014, p. 263). Es posible que, en Madrid, hacia 1618-1620, se estuviera pensando en la posibilidad/necesidad de llevar a cabo una actuación política, militar y de colonización que reivindicara los territorios amazónicos, más allá de la línea de Tordesillas, para la rama castellana de la Monarquía Hispánica. Las contradicciones, dudas, recelos mutuos, etc., estaban servidos. 
El plan para la región del Maranhão-Grão Pará se expresa claramente en la carta enviada por el rey al virrey de Portugal el 20 de junio de 1618. En ella el rey manifestaba la decisión de separar el gobierno de Maranhão del de Brasil, y pedía que el antiguo gobernador Gaspar de Sousa propusiese nombres de personas que tenham experiencia do gentío e daquelas terras. Pedía también que se formara ya una estructura jurídico-administrativa para el nuevo estado, con un provedor da fazenda y un almojarife con su escribano correspondiente. Planteaba la necesidad también de que se enviaran religiosos para la conversión del "gentío" a la fe católica, misión que sería encomendada a los franciscanos del capítulo de San Antonio. Una petición realizada por los carmelitas para el mismo efecto fue rechazada por el rey, quien también se mostró reticente a que fuesen los jesuitas los protagonistas del esfuerzo misional en la zona ${ }^{7}$. La financiación de todo este proyecto debería realizarse a través de las rentas de los décimos de Brasil. El rey hacía una recomendación para una mayor eficacia en la utilización del dinero recaudado y su cuantía: debería realizarse el contrato de arrendamiento en Portugal y no en Brasil y se debería pedir la cantidad de doze contos (doce millones de reales), cantidad considerada suficiente para sufragar la conquista. Como el envío del dinero desde Brasil a Portugal para su posterior remisión a Maranhão se dilataría mucho, el rey ordenaba que el gobernador del Estado de Brasil estimase qué cantidad era necesario enviar para la nueva conquista y como habría de conseguirla de manera urgente. Finalmente pedía que se le enviara una hoja con todos los ingresos y gastos de Brasil para ver qué cantidad "sobraba" y podía ser utilizada en la conquista ${ }^{8}$. La importancia de la incorporación de Maranhão se puede comprobar en la orden que se mandó desde Madrid para que se investigara qué cantidades sobraban de los contratos de la pimienta para que pudieran ser utilizadas en la conquista de ese territorio, una vez que se hubieran cubierto los gastos para armar las flotas a Indias ${ }^{9}$.

La colonización del territorio debería llevarse a cabo con inmigrantes portugueses e irlandeses católicos. Para eso se aprobó el proyecto de colonización ofrecido por un tal George de Lemos Betancor para poblar la región con familias de azorianos ${ }^{10}$. Bien sabían las autoridades en Lisboa y en Madrid que el aprovechamiento económico de un territorio en Brasil no se podía llevar a cabo sin esclavos africanos. Esto es lo que había pedido Diego de Cárcamo en sus condiciones para aceptar el cargo de gobernador del nuevo estado. Para ello se ordenó al virrey de Portugal que diese los pasos necesarios para llevar a la región esclavos de Guinea o de Angola. El virrey mandó provisión al respecto al Conselho da Fazenda para que aprobase la importación a Maranhão de esclavos de Angola "por cuenta de V. Magestad" o por cuenta del contratador de esclavos de Angola. Es sin duda excepcional que el rey se involucrara en una conquista hasta el punto de ser él mismo quien sufragara la introducción de esclavos ${ }^{11}$.

De toda esta estrategia, el plan más importante y duradero para la región del Maranhão-Grão Pará sería la reforma administrativa decidida y anunciada en 1618: la separación de toda la zona del resto de Brasil y la conversión de este territorio en un "Estado" con las mismas atribuciones que el "Estado do Brasil", previamente existente y que tenía en Salvador su sede gubernativa. La del Estado do Maranhão seria en primera instancia São Luis, adonde debía ir el primer gobernador nombrado para la zona, el español Diego de Cárcamo, que sin embargo, nunca llegó a ocupar su puesto. El hecho de que fuera un español el primero nombrado para el cargo, además de quebrar las disposiciones de Tomar de 1581, nos da una idea de hasta qué punto la corona española consideraba la colonización de la región amazónica como un problema propio, que debería llevar adelante sin el concurso de las autoridades portuguesas. Esto también era el reflejo de aquellas dudas ya mencionadas sobre si ese territorio estaba o no dentro de la línea de Tordesillas.

Sobre la cuestión de la división de la América portuguesa en dos grandes unidades políticas aún hay mucho por investigar. Ninguno de los grandes trabajos realizados últimamente sobre la región y sobre la conquista han tratado de manera profunda este asunto. Aún no tenemos claras totalmente las razones de la separación de todo este territorio en otra entidad administrativa diferente del Estado do Brasil. Es obvio que las peculiaridades geográficas tuvieron un papel importante, pues las dificultades para la navegación desde y hacia Salvador hacía muy complicadas las comunicaciones con la capital administrativa de la colonia. Sin embargo, hay que tener en cuenta tanto la estrategia general habsbúrguica para la región, ya comentada, como los intereses locales, pues la conquista fue llevada a cabo por importantes elementos 
pernambucanos que muy probablemente preferían cierta autonomía de la tutela de Salvador. Cuando se habla de una "división" del territorio, en realidad estamos hablando del nombramiento de un gobernador diferente, separado y autónomo de Salvador de Bahía para este territorio. Eso es exactamente lo que el rey ordenaba en escrito enviado al virrey de Portugal en 1618, donde le hacía saber que debía consultar tal cuestión con el "comité de expertos" formado por Alexandre de Moura, Gaspar de Sousa y Diogo de Meneses $^{12}$. La razón esgrimida era que se tendría una mejor gestión de los socorros necesarios para la conquista de aquellas tierras "tan dilatadas". Se instaba al gobernador de Brasil, Luis de Sousa, a buscar la mejor forma de financiación de ese nuevo estado y cómo habría de realizarse esta financiación en caso de que la separación de los territorios no fuera posible ${ }^{13}$.

La cuestión del nombramiento de un gobernador autónomo para una extensa región no era algo nuevo en la administración de la colonia portuguesa en América. Ya en 1609 Francisco de Sousa había ido a São Paulo con título de gobernador de las Capitanias de baixo, o Repartição do Sul, territorio que comprendía las capitanías de Río de Janeiro, Espirito Santo y São Vicente (Sanches, 2005). La motivación para esta separación fue la visita a la corte de Francisco de Sousa en 1606, donde presentó toda una argumentación, concretada en "Apuntamientos", sobre la existencia de minas de plata en la zona del interior de São Vicente ${ }^{14}$. Hay ciertas analogías con el caso de Maranhão. En 1616 el rey escribía una carta al virrey de Portugal, el arzobispo de Lisboa Miguel de Castro, informándole del éxito que habían tenido las pruebas realizadas para sacar cobre de "piedras que vinieron de Maranhão", considerando que de aquella conquista se podría sacar "todo el cobre necesario para la artillería de las armadas y fortalezas de ese reino"15. Podemos imaginar cómo se recibió esta noticia en un momento en que existían dificultades muy serias para el apresto de las flotas y naos de la Carreira da India ${ }^{16}$.

La práctica de la separación de territorios, haciéndolos "independientes" de Salvador, tanto en el caso de la Repartição do Sul como en el caso de Maranhão, tiene que ver con la especial consideración que la corona otorgaba a esas regiones en concreto, tanto por su potencialidad económica, al encontrarse supuestamente en ellas yacimientos mineros, o por su especial y relevante papel estratégico, como es el caso de Maranhão, considerada ya como una región fundamental para la organización de la defensa de las flotas de Indias, como posible punto de salida de la plata o potencial cuña de entrada de enemigos de la corona en las posesiones americanas, con la posibilidad de una entrada hacia Perú. La importancia de la división fue tal que se mantuvo así (excepto para los años 1652-54) hasta los años 70 del siglo XVIII.

Por otro lado, la conquista de Maranhão tuvo un significado fundamental para varias familias criollas que accedieron a cargos del más alto nivel, como recordó Alberto Gallo. El caso de los Albuquerque Coelho fue el más significativo. Eran estos parientes de los donatarios de Pernambuco y habían participado previamente en la conquista de Paraíba. El primer comandante de la conquista de Maranhão fue Jerônimo de Albuquerque. Feliciano Albuquerque Coelho de Carvalho fue capitán en Paraíba. Su hijo Francisco Coelho se convirtió en el primer gobernador real del estado de Maranhão en 1624, tras la imposibilidad de ocupar el cargo por parte de Diego de Cárcamo, tanto por su elevada edad como por sus conexiones antonianas (había sido secretario del Prior do Crato). A la anomalía de nombrar un español para el puesto de gobernador se sumó aquí que Francisco Coelho era pernambucano, siendo así que los puestos de este rango eran siempre ocupados por portugueses peninsulares. Posteriormente los hijos de Francisco serán también gobernadores de Maranhão en algunos momentos (Gallo, 1999). Otra derivación de la incorporación de Maranhão a los territorios del rey católico fue la revitalización del sistema de capitanías donatarias, que había decaído de manera muy significativa desde la donación de las primeras en la tercera década del siglo XVI. Con beneplácito del rey Felipe IV, Francisco Coelho otorgó las capitanías de Cumá, Caeté y Cumaná a diversos allegados suyos durante los 15 años que ejerció su cargo ${ }^{17}$.

Los años posteriores a la conquista están llenos de peticiones de soldados y allegados de Albuquerque que participaron en la campaña solicitando mercedes a la corona. Al hijo mayor de Jerónimo el rey le concedió en 1620 el primer puesto de capitán que quedara vacante entre las capitanías de Río de Janeiro, 
- LA CONOUISTA Y COLONIZACIÓN DE MARANHÃO-GRÃO PARÁ:

Rio Grande y Paraíba, además de cinco leguas de tierras en concesiones de sesmarías en Maranhão ${ }^{18}$. Como muchos de los participantes eran extranjeros y levantaban dudas sobre si estaban "prohibidos" (excluidos de las rutas comerciales o de la residencia en la América portuguesa por los diversos edictos promulgados al respecto) o si tenían problemas "de nacimiento" (no ser de origen judío), se intercambiaron cartas con los asesores en Lisboa (Gaspar de Sousa, Diogo de Menezes) sobre la idoneidad de algunas de las peticiones. Una de ellas, referente a un tal Constantino Carrasa, fue aprobada por el rey tras el informe favorable de Gaspar de Sousa ${ }^{19}$.

Casi ya al final del periodo de la unión dinástica, entre 1637 y 1639, Pedro Teixeira llevó a cabo su épico viaje aguas adentro del Amazonas, consiguiendo contactar con Quito. El capitán portugués partió de São Luis en 1637 por órdenes del gobernador Jácome Raimundo de Noronha. Este viaje no se entendería sin los antecedentes de expansión llevados a cabo por los franciscanos en los años anteriores, comenzando desde Quito y el río Napo. En efecto, desde 1633 salieron hasta 4 expediciones de franciscanos desde la capital andina hacia el este, con el objetivo de evangelizar a las poblaciones del otro lado de la sierra. Siguiendo el curso del río Napo llegaron a la zona habitada por los indios "encabelludos" que asesinaron al capitán español Juan Palacios. Una expedición de 5 soldados españoles y uno portugués, junto con los frailes franciscanos Domingo de Brieva y Andrés de Toledo siguieron aguas abajo hasta encontrarse con el fuerte portugués de Gurupá, mencionado anteriormente. Siguieron hacia Belém do Pará y finalmente arribaron a la entonces capital del Estado do Maranhão, São Luis ${ }^{20}$. Allí les recibió Jácome Raimundo de Noronha, que se había autoproclamado gobernador circunstancial con el apoyo de las cámaras de São Luis y Belém tras la muerte de Francisco Coelho en 1636. Según el relato de Cristóbal de Acunha, Jácome decidió cumplir el mandato que hizo Felipe IV de reconocimiento y posesión del río Amazonas, encomendando la realización de una gran expedición al capitán Pedro Teixeira, hombre de gran experiencia en la zona, que había participado en la conquista de Maranhão y en el desalojo de holandeses e ingleses de los distintos fuertes del interior. Teixeira partió en julio de 1637 con 47 canoas, 70 portugueses, 1.200 indios, 4 de los castellanos que habían descendido el río y el jesuita Domingo de Brieva que había llegado hasta São Luis

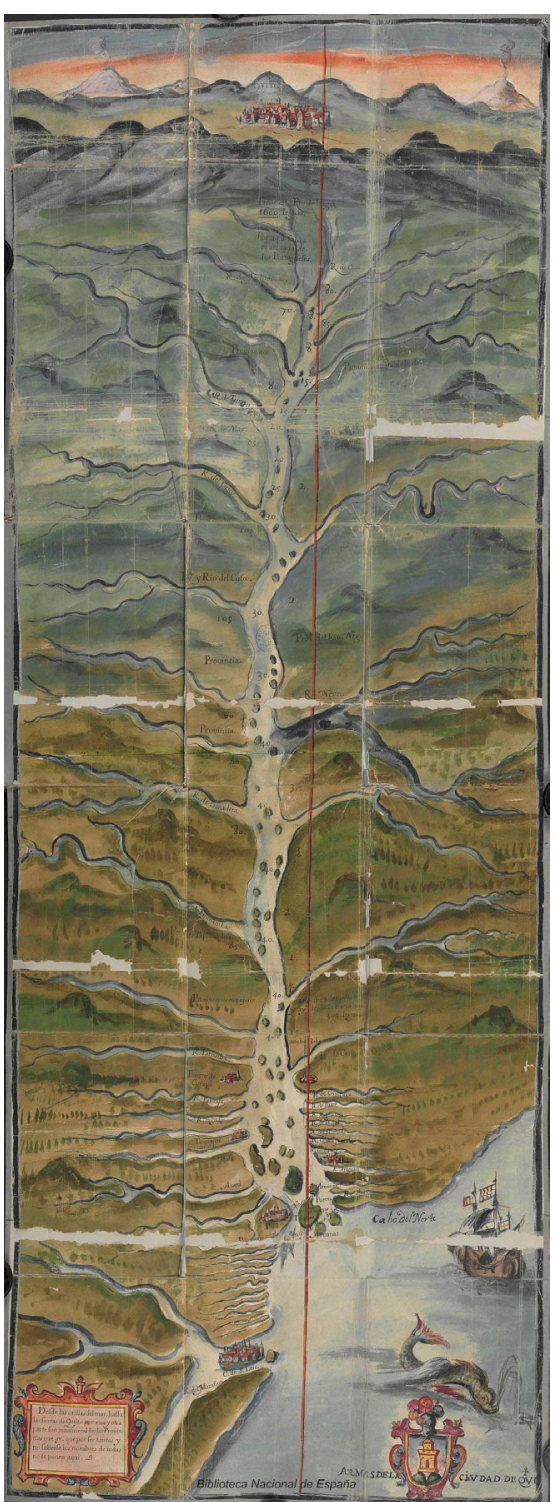

Imagen 2. Saavedra y Guzmán, M. de (1639). Mapa del río Amazonas y su cuenca desde Quito hasta la desembocadura en el mar. Madrid, Biblioteca Nacional de Madrid. Recuperado de [http://www.bne.es/es/AreaPrensa/ MaterialGrafico/Exposiciones/Historico/2017/ exposicion-cartografias/index.html]. Consultado [04-01-2019]. 
ese mismo año, probablemente como guía ${ }^{21}$. La historia posterior es suficientemente conocida: llegaron a Quito y fueron recibidos por el presidente de la audiencia, que indagó sobre los objetivos de su viaje y alertó a las autoridades de Madrid sobre la posible intención portuguesa de enseñorearse del Gran Río Amazonas. Entre los varios relatos de la jornada de Teixeira destaca el de Cristóbal de Acuña, jesuita que acompañó a Teixeira en su viaje de regreso a Pará desde Quito, y la "Relación anónima", pero atribuida al jesuita Alonso de Rojas, que el presidente de la Audiencia de Santa Fe, Martín de Saavedra y Guzmán envió a Madrid en 1639. Esta última contenía un extraordinario mapa, que reproducimos (Imagen 2), sobre el recorrido del río Amazonas desde las fuentes en los Andes, supuestamente cerca de Quito, hasta su desembocadura.

Como es sabido, la práctica coincidencia del viaje con los sucesos de la proclamación del Braganza en Lisboa como João IV y la posterior "restauración" portuguesa, llevaron a una interpretación como que la expedición era un desafío de los locales a la corona española, anunciando así el movimiento en Portugal. Sería, según Jaime Cortesão, una expedición de corte "nacionalista y pre-revolucionaria", significando al mismo tiempo un desafío contra los Austria y una defensa portuguesa ante los intentos de los Habsburgo de tomar propiedad de toda la región amazónica ${ }^{22}$. Guida Marques se ha ocupado de demostrar lo contrario, dejando claro que, lejos de ser un movimiento de desafío a la estrategia habsbúrguica en la región, lo que la expedición de Pedro Teixeira demostraba, muy al contrario, era la capacidad y los deseos de integración entre los dos territorios, español y portugués, en esa zona remota del continente americano, llevando a cabo así el proyecto presentado por tantos memoriales enviados a la corona, y que finalmente parecía ser posible: el de una integración entre el Atlántico y el virreinato del Perú a través del territorio del Amazonas (Marques, 2014, p. 273). Que futuros planes de integración no se llevaran a cabo fue una derivación de la separación post 1640 y no un síntoma de la identificación con la causa bragancista.

Es posible afirmar, por tanto, que fue durante la unión de las coronas ibéricas, entre 1580 y 1640 , que se pusieron las bases para la integración y colonización efectiva del inmenso territorio amazónico. Nuevas y recientes interpretaciones nos deparan una nueva visión del papel primordial que tuvo el territorio amazónico durante estos años de la mal llamada "Unión Ibérica". Lejos de las interpretaciones clásicas que en clave nacionalista explicaron que durante este periodo los Habsburgo de Madrid habían descuidado la defensa de los territorios portugueses a causa de los muchos compromisos bélicos en Europa y en casi todo el planeta, hemos visto que hubo una muy grande preocupación por arrebatar el territorio a los enemigos de la Monarquía Hispánica y por mantenerlo bajo su dominio. Si bien no se puede decir que el esfuerzo bélico y financiero de la conquista corriera por cuenta del rey español, sí se puede constatar que las iniciativas locales fueron recibidas y apoyadas con entusiasmo por parte de las autoridades imperiales. Hubo profundas reticencias sobre a cuál de las dos coronas, portuguesa o castellana, correspondía el territorio amazónico, pero el objetivo común de expulsión de los enemigos "herejes" y las posibilidades que se abrían si se llevara a cabo el objetivo de conectar la desembocadura del Amazonas con Perú por vías fluviales, hicieron que esos temores y reticencias se desvanecieran y surgieran grandes proyectos comunes para la colonización del territorio, como se pudo ver a partir de 1618. Este gran proyecto solo tuvo como consecuencias duraderas dos hechos importantes: por un lado, la división del territorio de la América portuguesa en dos grandes regiones administrativas, Estado do Brasil y Estado do Maranhão, después Estado do Grão Pará-Maranhão, que perduraría hasta bien entrado el siglo XVIII. Por otro lado, la reivindicación portuguesa de todo el territorio amazónico en 1750, cuando se discutieron los límites de cada uno de los territorios, español y portugués, en América. El representante portugués en las negociaciones, Alexandre Gusmão, para afianzar su posición, reclamó como portugueses los territorios aguas arriba del Amazonas, aquellos que había recorrido Pedro Teixeira en su expedición culminada en 1639. Incluso llegó a afirmar que la población de Franciscana, supuestamente fundada por Teixeira, estaría en la desembocadura del Napo, mucho más al interior del punto que reivindicaba para Portugal. Este argumento y la interpretación en clave nacionalista de los sucesos de 1640 y, en general, del periodo de la Unión Dinástica, han nublado lo que en realidad fueron grandes proyectos de integración, presentados como factibles y deseables por parte de los locales y fomentados por una corona que deseaba, ante todo, una uniformidad religiosa y una seguridad para el aprovechamiento económico de sus inmensos territorios americanos. 


\section{NOTAS}

1 Parte de la investigación para este artículo ha sido financiada con los proyectos del MINECO: Redes políticas, comerciantes y militares en Brasil durante la Monarquía Hispánica y sus postrimerías (1580-1680)" ref. HAR2012-35978 (hasta 2016) y "Circulación de personas, libros, objetos y noticias entre Brasil y los territorios de la Monarquía Hispánica (1580-1668)", desde 2017, HAR2016-78099-P.

2 Archivo General de Simancas, (AGS) Secretarías Provinciales, (SSPP), libro 1552, fol. 378, Carta de Antonio Paez en la que declara que por petición del virrey arzobispo de Lisboa "Ihe encarregou da parte de V. Magde. que agasalhase o capitao francés que entregou o Maranhao, o que fez a sua custa com grande despessa de sua fazda., perto de tres anos continuos".

${ }^{3}$ Véase al respecto, Biblioteca da Ajuda, BA, 51.VIII.19, fol. 166v. Carta do Bispo D. Pedro de Castilho a El-Rei. 2 de junio de 1605

4 "Derrota del río de las Amazonas, dada por el Capitán Manuel de Sosa Dessa al Señor Virrey" Archivo General de Indias (AGI), Patronato, 272, R. 5, Fols. 57-59/1615. Según apunta Alírio Cardoso (2012), el memorial fue traducido por el mismísimo secretario de Felipe III, Tomás Gracián Dantisco.

5 AGI, Quito,158, 30 de agosto de 1623, "Descripción de la fortaleza erigida por Bento Maciel”, fols. 54- 56.

6 Brandão, A. Fernandes (atribuido), Diálogo das grandezas do Brasil, (1618) apógrafo de Leiden, Biblioteca de la Universidad de Leiden, Códice VGGQ14, fols. $12-12 \mathrm{v}$.

7 AGS, SSPP, libro 1516, fol. 109v. Procurador da Compa do Jesus do Brasil, 15 de agosto de 1618. La petición de Ios carmelitas en AGS, SSPP, libro 1516, fol. 63v., 23 de mayo de 1618.

8 AGS, SSPP, libro 1516, fol. 78 e ss. Carta del rey al virrey de Portugal. 20 de junio de 1618.

9 AGS, SSPP, libro 1552, fol. 128. 4 de abril de 1620 , Carta del virrey marqués de Alenquer al rey. El marqués informó que en el año de 1619 los diversos contratos de la pimienta, derecho y fletes de las naos, rindieron 83.000 cruzados. De ellos deberían salir los "aprestos" para los diferentes gobernadores de Brasil, Maranhão, Angola y Mina, lo que manifiesta que ya se contemplaba la existencia de este estado y su equiparación con los demás de la corona de Portugal. También se habla de este asunto en una carta del virrey de Portugal al rey del 2 de mayo de 1620: "El virrey al rey (sobre 83 mil cruzados que sobejarao do procedido da pimenta, direito e fretes das naos que vierao da Yndia o ano de 619". AGS, SSPP, libro 1552, fols. 179-180.

10 AGS, SSPP., libro 1516, fol. 11v. 1 de febrero de 1618. AGS, SSPP, libro 1474, Consulta sobre una petición de Jorge de Lemos Betancor, 3 de junio de 1620, fols. 406 a 410. Para este y otros proyectos de colonización ver Marques, G., "En los confines...” págs. 255-56.
11 AGS, SSPP., libro 1552, fol. 128, 4 de abril de 1620. El virrey al rey.

12 Sin duda fue este comité el que decidió en última instancia la separación.

13 AGS, SSPP., libro 1516, fol. 11 v., 1 de febrero de 1618, Consulta del rey al virrey de Portugal. La consulta se reiteraba el 9 de mayo del mismo año, por falta de respuesta del virrey, AGS, SSPP., libro 1516, fol. 58v.

${ }^{14}$ AGS, SSPP, libro 1466, fols. 327 a 332v., Apuntamientos de Francisco de Souza, julio de 1607. Véase también la tesis doctoral de José Carlos Vilardaga: "São Paulo na órbita do Império dos Felipes: conexões castelhanas de uma vila da América portuguesa durante a União Ibérica (1580-1640)", São Paulo, Tesis doctoral, USP, 2010.

15 AGS, SSPP, Libro 1513, 13 de julio de 1616. El rey al gobernador de Portuga

16 Como se advierte en la carta del virrey Salinas al rey en junio de 1620 , donde habla de estas dificultades y los posibles remedios. Uno de los problemas es abastecer el cobre para la artillería de las naves. AGS, SSPP, Libro 1552 , fols. 109 a 204

17 AGS, SSPP, Libro 1552, fol. 230.

18 AGS, SSPP, libro 1517, fol. 34v. 26 de agosto de 1620. Respuesta a la consulta de Antonio de Albuquerque.

${ }^{19}$ AGS, SSPP., libro 1552, fol. 290, 30 de marzo de 1620. Gaspar de Sousa sobre dom Constantino Carrasa.

20 El relato de las expediciones franciscanas está en Biblioteca Nacional de Madrid (BNM) Manuscrito 2950; Micro 5164, Nuevo descubrimiento del río de Marañón llamado de las Amazonas, hecho por la Religión de San Francisco. Año de 1651, Siendo missionario el P. fr. Laureano de la Cruz y el P. fr. Juan de Quinquoces, escrito por la obediencia de los Superiores en Madrid, año 1653, por Fr. Laureano de la Cruz..., hijo de la provincia de Quito.

21 El dato es de Filho, Synesio Sampaio Goes, "Contextualização Histórica" en Lima, Sérgio Eduardo Moreira y Coutinho, Maria do Carmo Strozzi (orgs.), Pedro Teixeira, a Amazônia e o Tratado de Madri, Brasília: FUNAG, 2016, p. 28. En el relato de Fray Laureano de la Cruz se habla de 40 canoas.

22 Cortesão, Jaime, "O significado da expedição de Pedro Teixeira à luz de novos documentos", en Lima, Sérgio Eduardo Moreira y Coutinho, Maria do Carmo Strozzi (orgs.), Pedro Teixeira, a Amazônia e o Tratado de Madri, Brasília: FUNAG, 2016, páginas 39-58. En esta publicación de la Fundação Alexandre Gusmão, de fechas recientes, se sigue considerando válida la interpretación nacionalista, sin tener en cuenta los más recientes estudios sobre el tema, que la desmienten categóricamente. 


\section{REFERENCIAS BIBLIOGRÁFICAS}

Allen, P. (2001). Felipe III y la Pax Hispanica, 1598-1621: el fracaso de la gran estrategia. Madrid: Alianza Editorial.

Boogaart, E. (1992). La expansión holandesa en el Atlántico. Madrid: Mapfre.

Brege, B. A. (2014). The Empire that wasn't. The Grand Duchy of Tuscany and Empire, 1574-1609. Tesis doctoral, University of Stanford, California, United States.

Cardoso, A. (2008). Notícias do norte: primeiros relatos da presença holandesa na Amazônia brasileira (século XVII). Nuevo Mundo Mundos nuevos. Débats. Recuperado de [https://journals.openedition.org/nuevomundo/43703]. Consultado [04-01-2019].

Cardoso, A. (2012). Maranhão na Monarquia Hispânica: intercâmbios, guerra e navegação nas fronteiras das Índias de Castela (1580-1655). Tesis doctoral, Universidad de Salamanca, Salamanca, España.

Chambouleyron, R. (2006). Conquista y colonización de la Amazonia portuguesa (siglo XVII). En Santos Pérez, J. M. \& Petit, P. La Amazonia brasileña en perspectiva histórica. Salamanca: Ed. Universidad de Salamanca.

Cortesão, J. (2016). O significado da expedição de Pedro Teixeira à luz de novos documentos. En Lima, S. E. M. \& Coutinho, M. do C. S. (Orgs.). Pedro Teixeira, a Amazônia e o Tratado de Madri. Brasilia: FUNAG.

Costa., C. X. de A. da G. e (1985). Receita e despesa do Estado do Brasil no Periodo Filipino. Aspectos Fiscais da Administração Colonial. Dissertação de Mestrado, Universidade Federal de Pernambuco (UFPE), Recife, Brasil.

Edmunson, G. (1903). The Dutch on the Amazon and Negro in the Seventeenth Century. English Historical Review, 18(72), 642-663.

Filho, S. S. G. (2016). Contextualização Histórica. En Lima, S. E. M. \& Coutinho, M. do C. S. (Orgs.). Pedro Teixeira, a Amazônia e o Tratado de Madri. Brasilia: FUNAG.

Gallo, A. (1999). Aventuras y desventuras del gobierno señorial en Brasil. En Carmagnani, M. (Org.). Para una historia de America (Vol. II). Los nudos I. México: Fondo de Cultura Económica.

García, B. (1996). La Pax Hispanica. Política exterior del Duque de Lerma. Leuven: Leuven University Press.

Garrido, C. (1940). Fortificações do Brasil. Subsídios para a História Marítima do Brasil (Vol. III, 279-459). Rio de Janeiro: Imprensa Naval.

Klooster, W. (2016). The Dutch Moment: War, Trade, and Settlement in the Seventeenth-Century Atlantic World. Ithaca Cornell: University Press.
Marques, G. (2014). En los confines del imperio hispanoportugués. La conquista del Marañon y del Gran Pará durante la unión ibérica. En Shaw, C. M. \& Martínez Torres, J. A. España y Portugal en el Mundo. Madrid: Ed. Polifemo.

Moreno, D. de C. (1955). Livro que da Razão do Estado do Brasil- 1612. Recife: Arquivo Público Estadual.

Olival, F. (2008). Felipe II, de "cognome" o Pío. Lisboa: Temas e debates.

Salvado, J. P. \& Münch Miranda, S. (2001). Cartas para Alvaro de Sousa e Gaspar de Sousa. (1540-1627). Lisboa: Comissão Nacional para as Comemorações dos Descobrimentos Portugueses.

Salvador, F. V. do (1627). História do Brasil (ed. 2014). São Paulo: Poeteiro Editor Digital.

Sanches, M. G. (2005). O Rio de Janeiro e a "Repartição do Sul" no período filipino: consolidação e expansão da colonização. Revista do Instituto Histórico e Geográfico Brasileiro, 426, 105-146.

Vilardaga, J. C. (2010). São Paulo na órbita do Império dos Felipes: conexões castelhanas de uma vila da América portuguesa durante a União Ibérica (15801640). Tesis doctoral, Universidade de São Paulo (USP), São Paulo, Brasil.

Wright, A. F. P. de A. \& Mello, A. R. de. (1997). O Brasi no período dos Filipes. En Buarque de Holanda, S. (Ed.). História Geral da Civilização Brasileira, tomo I, vol. 1. Río de Janeiro: Bertrand Brasil. 